\section{Quanto vale um ofício no exercício do} bom governo?

\author{
Maria Fernanda Bicalho[1]
}

Resenha recebida em 28 de novembro de 2016 e aprovada para publicação em 30 de novembro de 2016. [1] Instituto de História da Universidade Federal Fluminense (UFF) Niterói (RJ) - Brasil. E-mail: mfbicalho@uol.com.br
$\mathrm{M}$

érito, venalidade e corrupção não são temas distantes, no tempo e no espaço, de nossa experiência cotidiana no Brasil atual. Tampouco temas exclusivamente contemporâneos, embora tenhamos de ter cuidado para não incorrermos em anacronismo ao discutir essas três concepções e práticas em nosso passado colonial. Os anacronismos podem surgir ao tentarmos transferir noções próprias do Estado liberal - e democrático - para vivências em que, além da fluidez na distinção entre as esferas do público e do privado, a lógica da nomeação para cargos administrativos passava pela gramática social do prestígio, pelo caráter pessoal e estamental das relações sociais e políticas, por noções como amor e amizade (Cardim, 1999) e, sobretudo, pela obrigatoriedade de retribuição do rei aos serviços prestados por seus vassalos. Retribuição que pressupunha mercês em distinções, ofícios, contratos, monopólios e todo tipo de privilégios; lógica integrante não só do poder do rei de agraciar os súditos - de dispensar a graça - , mas da "justiça distributiva" que, segundo Fernanda Olival, era quase um modo de vida para diferentes setores do espaço social português e do mundo ibérico em geral, envolvendo não só membros da nobreza, mas também de grupos sociais mais baixos. (Olival, 2001, p. 21).

Essa especificidade do Antigo Regime levou a que muitos historiadores negassem a existência de uma percepção e clara distinção entre o que era lícito e ilícito na administração fazendária, no exercício do poder e da política e, sobretudo, nas relações sociais. A oposição weberiana entre Estado patrimonial e Estado burocrático e, consequentemente, entre as diferentes manifestações de uma dominação patrimonialista e outra de tipo racional-legal marcou consideravelmente nossa 
historiografia. O homem cordial, de Sérgio Buarque de Holanda (1983), e Os donos do poder, de Raymundo Faoro (1984), são dois exemplos marcantes dessa influência. No entanto, o próprio Faoro admite que, para os súditos americanos do rei de Portugal, havia um limite para aquilo que era considerado lícito ou ilícito. Atribui à situação colonial os "vícios" dos administradores portugueses e conclui com a verve afiada do padre Antônio Vieira: "Perde-se o Brasil, Senhor (digamo-lo em uma palavra), porque alguns ministros de Sua Majestade não vêm cá buscar o nosso bem, vêm cá buscar nossos bens..." (Faoro, 1984, p. 173).

O mesmo Vieira, no Sermão do bom ladrão, proferido em 1655 na Igreja da Misericórdia de Lisboa para uma plateia de ministros dos tribunais régios, admoestava que "nem os Reis podem ir ao Paraíso sem levar consigo os ladrões, nem os ladrões podem ir ao Inferno sem levar consigo os Reis". Denunciando a cumplicidade entre os reis e os ladrões, assim como o exercício do mau governo de funcionários régios que, sem mérito, eram nomeados por simples favores e espúrias negociações, e, ao não agirem em prol do bem comum da República, roubavam e vexavam os vassalos com o único intuito de enriquecimento próprio, Vieira insistia no imperativo cristão da restituição, uma vez que "sem restituição do alheio não pode haver salvação" (Vieira, 2000, p. 389-413).

Embora ainda pouco abordadas por historiadores portugueses e brasileiros, a ilicitude, a venalidade e a corrupção não estiveram totalmente ausentes de nossa produção acadêmica. Sobre a primeira há estudos acerca do contrabando, de Ernst Pijning e de Paulo Cavalcante, para o Rio de Janeiro, de Tiago Gil e de Fábio Kühn para as fronteiras sul da América portuguesa. Os primeiros tributários de uma genealogia historiográfica que tem nas teses dos anos de 1970-1980 sobre o Brasil sua matriz conceitual. Os segundos baseando-se na teoria das redes, quer mercantis, quer sociais. (Pijning, 2001; Cavalcante, 2006; Gil, 2007; Kühn, 2012) A venalidade de ofícios — tão bem conhecida nos domínios espanhóis e ultramarinos de Castela - tem sido ultimamente objeto de investigação, para Portugal e seus territórios de além-mar, de Roberta Stumpf e Nandini Chaturvedula (Stumpf e Chaturvedula, 2012).

Por outro lado, a atualidade do tema da corrupção no cenário político brasileiro motivou a publicação do livro Corrupção: ensaios e críticas. Em um dos dois únicos capítulos sobre o Brasil colonial - o outro é de Evaldo Cabral de Mello - Luciano Figueiredo, embora remeta-se à carência na historiografia brasileira "de investigações exaustivas dedicadas a estudos de casos”, chama a atenção para que há muito historiadores como Caio Prado Júnior e Charles R. Boxer afirmassem, o primeiro, em seu ceticismo, que a vida social e política da América portuguesa foi profundamente permeada pela dissolução nos costumes, inércia e corrupção nos dirigentes leigos e eclesiásticos; o segundo que as queixas acerca da rapacidade e venalidade dos funcionários régios foram tema constante da correspondência particular e oficial entre Brasil e Portugal por mais de três séculos (Figueiredo, 2008, p. 209-218).

Nos últimos anos, Adriana Romeiro se debruçou sobre o conteúdo polissêmico do conceito de corrupção na época moderna, indagando-se sobre sua pertinência, constatando que 
a cultura política do Antigo Regime contava com um leque de formulações sobre as práticas ilícitas cometidas por governantes e funcionários régios. A partir da discussão de diferentes significados da palavra corrupção, em dicionários, tratados sobre a arte de bem governar, crônicas e outros escritos coevos dos séculos XVI ao XVIII, analisou as noções que estruturavam o imaginário do mau governo, levando à "corrupção do corpo místico". Sendo considerada um vício - e muitas vezes um pecado - a ambição desmedida dos governantes era objeto não apenas de condenação nas obras de moralistas e políticos, constava igualmente das queixas e representações dos vassalos ultramarinos ao rei (Romeiro, 2015, p. 6).

Porém, o que está aqui em causa não são as análises clássicas e recentes da historiografia brasileira sobre a corrupção nos tempos modernos, e sim o livro Mérito, venalidad y corrupción en España y América: siglos XVII y XVIII, organizado por Pilar Ponce Leiva, professora da Universidad Complutense de Madrid, e Francisco Andújar Castilho, da Universidade de Almería. Publicado em 2016, fruto de um projeto de investigação coletivo, o livro reúne 17 capítulos escritos por diferentes historiadores de várias instituições na Europa e na América, voltados sobretudo para o mundo hispano-americano. No que diz respeito a Portugal e ao Brasil, conta com a contribuição de Roberta Stumpf. O "Prólogo" é de Nuno Gonçalo Monteiro.

Seus organizadores há muito vêm se dedicando a temas correlatos, tanto em projetos de pesquisa envolvendo redes internacionais de investigação quanto em publicações. Estiveram juntos no livro organizado por Francisco Andújar Castillo e María del Mar Felices de la Fuente, El poder del dinero: ventas de cargos y honores en el Antiguo Régimen, no qual Pilar Ponce Leiva tem um capítulo sobre as dinâmicas sociais e consequências políticas da venda de cargos municipais em Quito, no século XVII (Ponce Leiva, 2011, p. 145-165). Na introdução ao presente livro, admitem que mérito, venalidade e corrupção são questões há muito abordadas, quer para a monarquia hispânica, quer para seus domínios ultramarinos, embora estejam hoje sujeitas a uma profunda revisão historiográfica. Essa obra é produto e testemunho disso. Seus autores convergem na crítica a como tem sido tratado, até muito recentemente, o tema da venalidade e, sobretudo, da corrupção, por um lado por aqueles que negam sua existência baseando-se na indefinição, na Europa da época moderna, entre o público e o particular; e, por outro, por quem entende ser a corrupção, pelo mesmo motivo, condição "natural" e indissociável, eixo inquestionável e estruturante das sociedades de Antigo Regime. Segundo os organizadores:

Se ha cuestionado mucho que en la época existiese de forma expresa el concepto de "corrupción", y más aún que tuviese las mismas connotaciones que en la actualidad. Los estudios disponibles demuestran, sin embargo, que tanto en la tratadística de la época como en los textos dicho concepto aparece con connotaciones similares a las actuales [...]. Esos mismos estudios corroboran que el término se refería de manera inequívoca a delitos punibles por la justicia, a los abusos de poder en beneficio de quien los cometía y en detrimento de los administrados. No obstante, el debate presenta muchas más aristas, pues va desde los autores que estiman que la corrupción era consustancial al ejercicio del poder en el Antiguo 
Régimen hasta quienes niegan su existencia "por no existir ni siquiera" el próprio término en la sociedad de la época. Pero más allá de essas consideraciones lo que parece incuestionable es que el proprio concepto de lo que entendemos por corrupción requiere un profundo debate, sobre todo para situar en contexto, y de acuerdo con las convenciones del sistema político, jurídico y social de Antiguo Régimen, lo que tratamos de estudiar. (Ponce Leiva e Andújar Castillo, 2016, p. 10)

A primeira parte do livro, Conceptos y valor de los méritos, inicia-se com o capítulo de María del Mar Felices de la Fuente sobre os méritos necessários para se ter o título de nobre em Castela, no qual a autora analisa uma das principais prerrogativas do rei: sua intervenção em assuntos de graça e mercês, assim como a importância dos méritos pecuniários na outorga de honras, títulos e dignidades. Domingo Marcos Giménez Carrillo debruça-se sobre as conferições e as distinções entre as "mercês dos hábitos" e de "títulos de cavaleiro" das ordens militares no reinado de Felipe V, demonstrando os pesos relativos entre o serviço pecuniário e o das armas. Amorina Villarreal Brasca, no capítulo sobre o provimento do VII conde de Lemos na presidência do Conselho de Índias (1603), revisita essa importante instituição voltada para os assuntos relativos aos domínios ultramarinos de Castela em um momento crucial para a monarquia hispânica. Guillermo Burgos Lejonagoitia analisa o funcionamento das designações para ofícios nas Índias de Castela entre 1701 e 1746, sem que o pagamento em dinheiro fosse o que mais importasse, e sim os demais méritos no serviço ao monarca. Já Antonio Jimenez Estrella indaga-se sobre o processo de estatização, profissionalização e burocratização do exército da monarquia dos Áustria durante o valimento do conde-duque de Olivares, momento em que a milícia se consolidou como uma das vias privilegiadas de ascensão social e de vinculação ao estatuto nobiliárquico por parte de homens sem méritos anteriores, ou cujo mérito consistiu em sua capacidade econômica de recrutar soldados. Encerra essa primeira parte o capítulo de Roberta Stumpf, no qual a autora, ao criticar os estudos que privilegiam a discussão da legislação e dão pouca importância às possibilidades reais de sua implementação, ou seja, às práticas dos governantes in loco, discute as ambiguidades da política pombalina, que se, por um lado, pretendeu "racionalizar" a provisão dos ofícios, dificultando sua patrimonialização, por outro, manteve a prática da venalidade em sua concessão, sobretudo em territórios ultramarinos.

A segunda parte do livro, El mercato de las ventas de ofícios, inicia-se com o estudo de Francisco Andújar Castillo, no qual o historiador discute a intensificação da venda de ofícios na segunda metade do século XVII como forma extra (ordinária) de financiamento da monarquia, e sua privatização na medida em que eram alienados perpetuamente, tornando-se "patrimônios móveis" de seus proprietários. Partindo dessa constatação, procura dar resposta à pergunta: como e quem vendiam os cargos; demonstrando o grande protagonismo das juntas e dos conselhos régios. O texto de Francisco Gil Martínez sobre ingressos venais e gastos cortesãos aborda o destino que se dava ao dinheiro decorrente da venda de ofícios durante o valimento do conde-duque de Olivares, período em que a venalidade, em termos 
quantitativos e qualitativos, conquistou sensível amplitude. Centra sua análise na construção do Palácio do Bom Retiro. Christoph Rosenmüller detém-se na formação de alianças políticas na Corte de Madri em fins do século XVII e começos do XVIII, que cercearam a prerrogativa dos vice-reis da Nova Espanha de prover em suas clientelas e criados os ofícios nas alcaidarias maiores, diminuindo, por meio da venda de ofícios, o poder das elites aristocráticas tradicionais em favor de uma maior influência da Coroa na seleção dos candidatos.

O terceiro bloco do livro, Debates sobre a ubicua corrupción: miradas y casos é dedicado à análise do próprio termo "corrupção" e de seus múltiplos significados - morais, políticos e sociais - na época moderna, assim como de uma miríade de práticas entendidas como abusivas pelos contemporâneos, expressões do "mau governo". Os dois primeiros capítulos, "Percepciones sobre la corrupción en la monarquía hispânica, siglos XVI y XVII", de Pilar Ponce Leiva, e "La moralidad de los mentirosos: por un estúdio comprensivo de la corrupción”, de Anne Dubet, têm um caráter teórico e conceitual. O primeiro, de acordo com sua autora, visa a

\section{[...] ofrecer una primera aproximación a lo que en los siglos XVI eXVII y en el ámbito hispâ- nico se percibía como "corrupción", "corrupto" o "corrompido". Más que reducir la corrup- ción a una categoría analítica precisa, parece útil reconocer que se trata de una categoría cultural — o socio-cultural -, asociada a un determinado conjunto de normas, a un sis- tema de valores y a una variada gama de prácticas sociales que pueden — o no - ir en con- sonancia entre si. (Ponce Leiva e Andújar Castillo, 2016, p. 193-194)}

Anne Dubet, a partir do mote da fiscalidade e da fraude, volta-se para a compreensão dos sentidos da corrupção e de sua polissemia de acordo com a cultura política do Antigo Regime, testando discursos e práticas, as razões dos indivíduos e as estratégias de repressão. Os três capítulos seguintes dedicam-se a estudos de caso que trazem para o leitor um amplo leque de possibilidades no tratamento da corrupção tanto na Europa quanto na América. Inés Gómez González debruça-se sobre os percones, alegações jurídicas de defesa utilizadas para fazer frente às acusações a don Pedro Valle de la Cerda - que, segundo Elliott, era o homem mais poderoso da Espanha depois de Olivares - feitas em visita ao Conselho da Fazenda em 1643. Já Sébastien Malaprade demonstra como era possível enriquecer em tempos de crise ao analisar o caso de Rodrigo Jurado, fiscal da Comisión de Millones do Conselho da Fazenda, cuja fortuna e prosperidade deveram-se às relações que mantinha com os homens de negócio e ao controle que exercia sobre os arrendatários e tesoureiros dos millones. Pierre Ragon, em seu estudo sobre o conde de Baños, vice-rei da Nova España entre 1660 e 1664 , aborda as inúmeras extorsões e malversações exercidas em seu governo, cuja denúncia por setores hierarquicamente inferiores poderia colocar em risco a arquitetura e a organicidade do corpo político da monarquia e de seu império.

Os três últimos estudos se deslocam do centro da monarquia e de suas instituições "palacianas" para suas diferentes "periferias", focando personagens com grande trânsito entre 
culturas distintas, hierarquias conflitantes e interesses diversos. José Luis de Rojas debruça-se sobre os "senhores" do império asteca que, depois da conquista espanhola, conservaram suas posições destacadas, ocupando quer os cabildos de índios, quer postos de intermediação na cobrança de tributos, praticando todo tipo de atos abusivos. José Manuel Díaz Blanco deteve-se nas cartas inéditas de um mercador sevilhano que, enviado em 1664 pelo Consulado de Sevilha em missão à Corte de Madri, denunciou o poder do dinheiro como o único meio de aceder aos ministros e tribunais da monarquia no reinado de Felipe IV. Guilhermina del Valle Pavón nos remete às práticas e artimanhas dos mercadores que realizavam as principais transações dentro e fora da Nova Espanha pelo controle que exerciam sobre a prata, principal moeda no comércio internacional na época moderna.

Para terminar, reitero o que os organizadores já haviam advertido na introdução ao livro, e que Nuno Gonçalo Monteiro, em seu prólogo, destaca. Se, nas últimas décadas, houve uma revalorização da importância do tema da corrupção, da venalidade dos ofícios e das honras na monarquia hispânica, as reflexões aqui presentes propõem uma renovação desses estudos em diferentes escalas. Demonstram que a intensidade dos méritos, o exercício da venalidade, as concepções e as práticas de corrupção não eram perfeitamente similares na Europa e nos mundos americanos. Havia sensíveis diferenças entre as monarquias portuguesa e espanhola e singularidades irredutíveis entre as Américas lusa e hispânica. Se, para as últimas - a monarquia e a América hispânicas -, temos tantos e tão bons estudos e reflexões, cabe a nós, historiadores de língua portuguesa nos dois lados do Atlântico, enveredarmos pela investigação desses temas, quer em sua percepção político-administrativa, quer em sua configuração social. A leitura de Mérito, venalidad y corrupción en España y América: siglos XVII y XVIII torna-se, portanto, não apenas um convite sedutor nesse sentido, é sobretudo um desafio ao diálogo, uma vez que seus capítulos podem ser lidos, em toda sua riqueza e complexidade, como uma irrecusável fonte de inspiração para novas pesquisas e publicações. 


\section{Referências bibliográficas}

BOXER, C. R. O império colonial português (1415-1825). Lisboa: Edições 70, 1981.

CARDIM, P. Amor e amizade na cultura política dos séculos XVI e XVII. Lusitania Sacra: Journal of the Catholic University of Portugal, 2. série, t. XI, p. 21-57, 1999.

CAVALCANTE, P. Negócios da trapaça. São Paulo: Hucitec, 2006.

FAORO, R. Os donos do poder. 6. ed. Porto Alegre: Globo, 1984. v. 1.

FIGUEIREDO, L. R. A corrupção no Brasil Colônia. In: BIGNOTTO, N.; STARLING, H; AVRITZER, L.; GUIMARÃES, J. (Org.). Corrupção: ensaios e críticas. Belo Horizonte: UFMG, 2008. p. 209-218.

GIL, T. L. Infiéis transgressores. Rio de Janeiro: Arquivo Nacional, 2007.

HOLANDA, S. B. de. O homem cordial. In: HOLANDA, S. B. de. Raízes do Brasil. 16. Alameda, 2012. p. 179-206. ed. Rio de Janeiro: José Olympio, 1983. p. 101-112.

KÜHN, F. Clandestino e ilegal: o contrabando de escravos na Colônia do Sacramento (1740-1777). In: XAVIER, R. C. L. (Org.). Escravidão e liberdade. São Paulo: Alameda, 2012. p. 179-206.

OLIVAL, F. As ordens militares e o Estado moderno: honra, mercê e venalidade em Portugal (1641-1789). Lisboa: Estar, 2001.
PIJNING, E. Contrabando, ilegalidade e medidas políticas no Rio de Janeiro do século XVIII. Revista Brasileira de História, v. 21, n. 42, p. 397-414, 2001.

PONCE LEIVA, P. La venta de cargos municipales en Quito en el siglo XVII: consecuencias políticas y dinâmicas sociales. In ANDÚJAR CASTILLO, Francisco y FELICES DE LA FUENTE, María del Mar. (Org.). El poder del dinero: ventas de cargos y honores en el Antiguo Régimen. Madrid: Biblioteca Nueva, 2011. p. 145-165.

; ANDÚJAR CASTILLO, Francisco (Org.). Mérito, venalidad y corrupción en España y América: siglos XVII y XVIII. Valência: Albatros, 2016.

PRADO JR., C. Administração. In: Formação do Brasil contemporâneo. 15. ed. São Paulo: Brasiliense, 1977. p. 298-340.

ROMEIRO, A. A corrupção na época moderna: conceitos e desafios metodológicos. Tempo, v. 21, n. 38, p. 1-22, jul. 2015.

STUMPF, R.; CHATURVEDULA, N. (Org.). Cargos e ofícios nas monarquias ibéricas: provimento, controlo e venalidade (séculos XVII-XVIII). Lisboa: Cham, 2012. VIEIRA, A. Sermões. Organização e introdução de Alcir Pécora. São Paulo: Hedra, 2000. p. 389-413. 